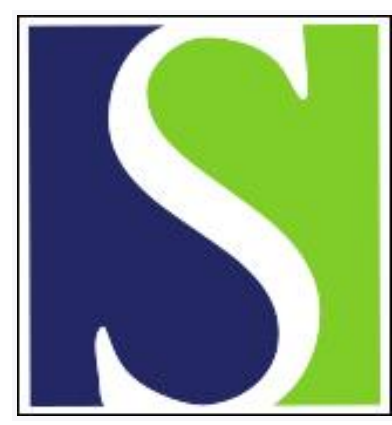

Scand J Work Environ Health 1979;5(4):379-385

https://doi.org/10.5271/sjweh.2652

Issue date: Dec 1979

Determination of quartz on membrane filters by X-ray diffraction.

by Tossavainen $\mathrm{A}$

Key terms: membrane filter; quartz; quartz analysis; X-ray diffraction

This article in PubMed: www.ncbi.nlm.nih.gov/pubmed/231821

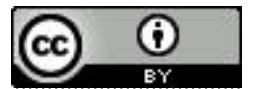




\title{
Determination of quartz on membrane filters by X-ray diffraction
}

\author{
by ANTTI TOSSAVAINEN, L.Sc. (Eng.) ${ }^{1}$
}

\begin{abstract}
TOSSAVAINEN, A. Determination of quartz on membrane filters by X-ray diffraction. Scand. j. work environ. \& health 5 (1979) 379-385. An X-ray diffraction method is described for the quantitative determination of quartz in dust samples. The analysis was done directly on a collecting cellulose ester membrane filter of the type used in an air sampler. Quantitation was achieved by the measurement of the quartz line intensities with a digital integrator and by the comparison of these values with those measured from calibration standards prepared on similar filters with water suspensions. The overall precision of the procedure was $8 \%$. When the method was applied to foundry dusts, the accuracy of the quartz analysis was found to be within $10 \%$ at the 1 - to $10-\mathrm{mg}$ level of total loading. The detection limit for quartz was below $0.1 \mathrm{mg}$.
\end{abstract}

Key words: quartz analysis, $\mathrm{X}$-ray diffraction.

Recognition of the health hazards due to prolonged exposure to airborne respirable silica has prompted the development of analytical methods for quartz based upon spectrophotometric $(3,17,18)$, infrared $(13$, $20)$, and X-ray diffraction $(1,2,3,4,5,6$, $7,8,9,10,11,14,21)$ techniques. The diffractometric method is attractive because it uses a small sample, is nondestructive and rapid, and all the individual crystalline mineral phases in a sample are potentially identifiable. In environmental monitoring, for which dust samples are collected on filters, the direct analysis of the dust on the filter would be convenient. Such a technique omits the removal and preparation of the dust sample for separate analysis and avoids errors associated with these procedures.

1 Department of Industrial Hygiene and Toxicology, Institute of Occupational Health, Helsinki, Finland.

Reprint requests to: Mr. Antti Tossavainen, Institute of Occupational Health, Haartmaninkatu 1, SF-00290 Helsinki, Finland.
The difficulties experienced in devising a suitable direct X-ray diffractometric method have identified a number of problem areas. Matrix effects such as mass absorption and interferences, particle orientation, size distribution and the quality of quartz standards are the most critical. Initial investigators $(4,19)$ limited the weight and composition of the loading on the filter so that the effect of sample mass absorption would be negligible and a linear relationship would exist between the quantity of the analyte and its diffraction line intensity.

The analysis of the thin layer specimens on organic membranes suffers from high $\mathrm{X}$-ray background scatter. This problem has been overcome by Bumstead with the use of pure silver filters and internal standardization (5). Leroux and co-workers have developed a method in which the silver line intensity is used to compensate for mass absorption effects in the surmounting dust (14). The direct use of the silver filters for the routine sampling of workplace air has several disadvantages 
however. The most important of these are connected with the retention and shielding properties of the filter material and with the need for silver line intensity measurements for every filter before use.

Mixed ester or polyvinyl chloride (PVC) membrane filters can be used for dust collection, and, after ashing or other suitable treatment, the dust sample is redeposited on a silver filter for "direct" X-ray diffractometry $(5,12)$. This approach greatly increases the laboratory work as compared with quartz determination on the sampling filter.

Nuclepore polycarbonate filters are very thin membrane filters with a low diffraction background, low mass absorption, small pore size, and high surface retention for collected dust. The theory of Altree-Williams forms the basis of an improved diffractometric technique for the use of Nuclepore filters in monitoring airborne quartz (2). The tendency for quartz particles to exhibit preferred orientation in thin layers deposited on smooth surfaces such as PVC or Nuclepore filters is responsible for the high variation of quartz line intensities (8). This orientation effect can only partly be compensated for by the rotation of the sample holder during the spectrometric measurement.

Since the late 1960s the Finnish Institute of Occupational Health has used Millipore membrane filters for aerosol sampling. Its preferred method for determining the respirable quartz concentration in workplace air has been that of modified Andreasen liquid sedimentation combined with X-ray diffractometry (21). The method is limited to a sample size of over 10 mg. The present study was initiated with particular reference to the foundry industry, for which the determination of quartz content in smaller samples is often needed. The task was to combine the most convenient membrane filter sampling with an accurate and rapid analysis. Dust samples were collected on a filter without any sizeselective classifier, and the filter was then subjected to X-ray diffraction measurement with digital line intensity calculation. The effects of mass absorption, interferences, particle orientation, and size distribution were assessed.

\section{MATERIALS AND METHODS}

\section{X-ray apparatus}

A Philips X-ray diffractometer was used comprising a generator (PW 1130), a vertical goniometer (PW 1050), a sample spinner (PW 1064), a graphite monochromator (PW 1152), an amplifier (PW 4280), a proportional counter (PW 1965), and a copper anode $X$-ray tube ( $P$ W 2103). A fixed divergence slit of $1^{\circ}$ and a receiving slit of $0.25^{\circ}$ were installed in the instrument. Membrane filters were mounted in the diffractometer and drawn taut with a concentric ring holder. The samples were analyzed at a tube power of $50 \mathrm{kV}$ and $20 \mathrm{~mA}$. Diffraction line intensity was measured with a Hewlett-Packard Integrator $3380 \mathrm{~A}$, while the spectra was scanned at an angle rate of $1 \% / \mathrm{min}$. The $\alpha$-quartz diffraction lines $4.26 \AA, 3.34 \AA$ and $1.82 \AA$ appeared at $2 \Theta$ angles of $20.85^{\circ}, 26.67^{\circ}$ and $50.15^{\circ}$, respectively. The integrator subtracted the background intensity using numerical peak fitting and interpolation. The net peak area reported by the integrator or the peak height measured by a recorder was alternatively used as the diffraction line intensity. A silicon blank was used as an external standard to correct for long-term instrumental drift.

\section{Standard preparation}

Both the samples and standards were collected on Millipore AAWP mixed cellulose ester membrane filters with a diameter of $37 \mathrm{~mm}$ and a pore size of $0.8 \mu \mathrm{m}$. The standards with known amounts of deposited material were prepared by liquid filtration. The dust suspension contained $100 \mathrm{mg}$ of dried material in $100 \mathrm{ml}$ of distilled water. The suspension was agitated with an ultrasonic stirrer which dispersed agglomerates. An aliquot of the stock suspension was pipetted and then filtered in a Millipore filtering apparatus (XX 15047). With $50 \mathrm{ml}$ of added water the dust was smoothly deposited over a circular area of $34 \mathrm{~mm}$ in diameter, which is the same as the effective filtering diameter of an air sampling monitor Millipore MAWP 037 AO. The membrane filters were then dried 
at $60^{\circ} \mathrm{C}$ for $2 \mathrm{~h}$. The apparent dust amount was calculated from the aliquot volume, and the result was checked by the weighing of the dried filter before and after the deposition. The filters had an electrostatic charge, and a static eliminator Staticmaster Ionizing Unit Model 2U 500 was used to discharge them.

The quartz standards were made of fractionated Fyle quartz, which originated from Fyleverken Ltd. (Eriksdal, Sweden) and was kindly supplied by the Aerosol Section of Arbetarskyddsstyrelsen, Stockholm. Most of the particles were less than $10 \mu \mathrm{m}$ in size, and the yield of those below $5 \mu \mathrm{m}$ was about $85 \mathrm{w}-0 \%$, as determined by liquid sedimentation. In Scandinavian countries this raw material is used by industrial hygiene laboratories as a standard for $100 \% \alpha$-quartz. The calcium fluoride and iron oxide used as quartz matrices were analytical grade Merck chemicals.

\section{RESULTS}

\section{Precision of standard preparation}

The precision of preparing quartz standards is affected by variation in the weighing and drying of the membrane filters, in the pipetting and filtering of the dust suspension, and in the mounting of samples in the diffractometer. Sixteen replicate standards were made of a mixture which contained $10 \%$ Fyle quartz in calcium fluoride. The calculated weights of the total deposits were $10 \mathrm{mg}$ each. Table 1 shows the variation of the peak areas for the $20.85^{\circ}$ and $26.67^{\circ}$ quartz lines and for the $28.30^{\circ}$ and $47.10^{\circ}$ lines of calcium fluoride. The relative standard deviations of the intensities ranged from 9.0 to $12.1 \%$ for the two quartz lines and from 4.4 to $5.7 \%$ for the two calcium fluoride lines. No significant difference between the variation of peak heights and that of peak areas could be found.

The alteration of filter weight during preparation was determined after $50 \mathrm{ml}$ of pure distilled water was sucked through ten separate filters. The weight difference caused by the treatment was less than $\pm 0.2 \mathrm{mg}$, a variation which corresponds to the imprecision of weighing a slightly hygroscopic filter. The water extractables are reported by the manufacturer to be less than $4 \%$ of the filter weight, if voluminous amounts of water are used (15). When the apparent weights of deposited material were calculated from suspension volumes and compared with the weighings, an average material loss of $3 \%$ was observed. The difference between the results ranged from -11 to $+4 \%$ for a series of 80 loaded filters. In the latter test the deposits varied from 1 to $50 \mathrm{mg}$ of dust.

The analytical precision of the diffraction intensity measurements is also shown in table 1 . The relative standard deviation of the quartz peak areas ranged from 8.0 to $10.3 \%$ in the case of ten replicate determinations on one filter loaded with

Table 1. Precision of preparing a quartz standard and measuring its X-ray intensities. The filter was loaded with $1 \mathrm{mg}$ of quartz mixed with $9 \mathrm{mg}$ of calcium fluoride. (Number of replicate samples $=16$, number of replicate measurements $=10$ )

\begin{tabular}{|c|c|c|c|c|}
\hline \multirow{2}{*}{\multicolumn{2}{|c|}{$2 \Leftrightarrow$}} & \multirow[b]{2}{*}{$\begin{array}{c}\text { Average peak } \\
\text { height } \\
(\mathrm{mm})\end{array}$} & \multicolumn{2}{|c|}{ Relative standard deviation $(\% / 0)$} \\
\hline & & & $\begin{array}{l}\text { Preparing, } \\
\text { mounting and } \\
\text { measuring a } \\
\text { standard filter }\end{array}$ & $\begin{array}{l}\text { Mounting and } \\
\text { measuring a } \\
\text { standard filter }\end{array}$ \\
\hline $20.85^{\circ}$ & quartz & 9 & 12.1 & 10.3 \\
\hline $26.67^{\circ}$ & quartz & 42 & 9.0 & 8.0 \\
\hline $28.30^{\circ}$ & calcium fluoride & 230 & 4.4 & 3.3 \\
\hline $47.10^{\circ}$ & calcium fluoride & 150 & 5.7 & 4.1 \\
\hline
\end{tabular}


$1 \mathrm{mg}$ of quartz and $9 \mathrm{mg}$ of calcium fluoride. When a series of quartz standards was prepared by air filtration, no differences in diffractometric response could be observed in comparison to suspension filtrated samples.

\section{Mass absorption}

Filters were prepared with different loadings and varying compositions of quartz in calcium fluoride. The diffraction intensities were measured from the three highest quartz lines, of which the results for the $26.67^{\circ}$ line are plotted in fig. 1. This family of curves can be used as calibration standards when the quartz concentrations of field samples are to be analyzed. At low loadings the relationship is linear. As the loading increases, a continuing deviation from linearity occurs due to the increasing absorption of the X-ray beam by the sample. For a diffractometer with a fixed divergence slit, line intensity I relates to total dust weight $m$ and quartz

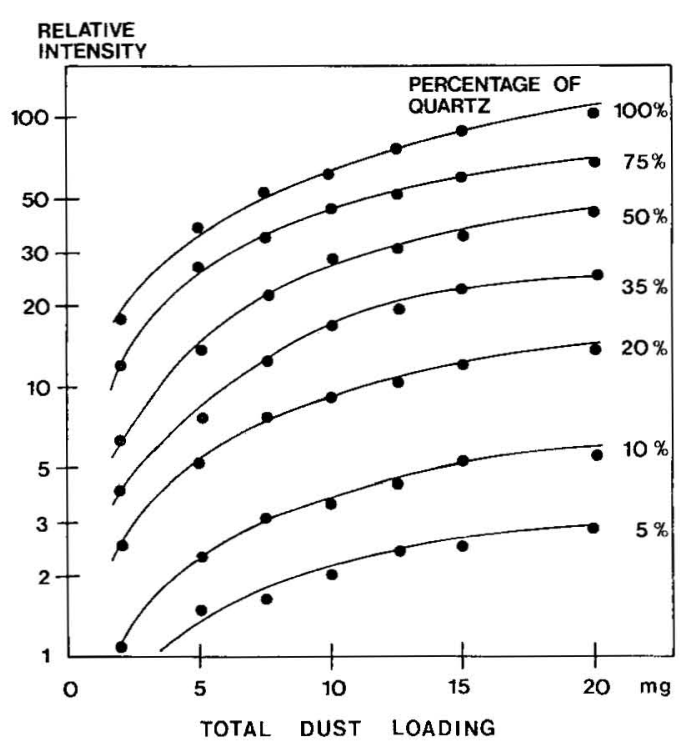

Fig. 1. Relative X-ray diffraction intensity for the quartz line $2 \Theta=26.67^{\circ}$ with different total dust loadings on a membrane filter. The curves are fitted to equation a with estimated parameters a and $\mathrm{b}$ (below).

$\begin{array}{lrrrrrrr}\text { C }(\mathrm{w} / \mathrm{w}) & 0.05 & 0.10 & 0.20 & 0.35 & 0.50 & 0.75 & 1.00 \\ \text { a }\left(\mathrm{I} / \mathrm{I}_{0}\right) & 67 & 72 & 78 & 81 & 97 & 109 & 137 \\ \text { b }(1 / \mathrm{g}) & 100 & 90 & 87 & 81 & 76 & 74 & 65\end{array}$

concentration $\mathrm{C}$ as follows:

$$
\mathrm{I}=\mathrm{aC}\left(1-\mathrm{e}^{-\mathrm{bm}}\right),
$$

where the parameters $a$ and $b$ should be evaluated separately for each dust composition. Their theoretical equations are $(1,12)$ :

and

$$
\mathrm{a}=\mathrm{k} / \mu
$$

$$
\mathrm{b}=(2 \mu / \mathrm{A}) \operatorname{cosec} \Theta,
$$

where $\mathrm{k}=$ constant, $\mu=$ mass absorption coefficient of the sample, $A=$ dust deposition area (larger than the irradiated area), and $\Theta=$ angle of incidence of the $\mathrm{X}$-ray beam to the sample.

For the assessment of the effects of differing sample matrices, two series of ten samples were prepared with dust deposits ranging from 2 to $20 \mathrm{mg}$. In the first series the dust mixture contained $5 \%$ quartz, $45 \%$ iron oxide and $50 \%$ calcium fluoride. The second mixture was composed of $15 \%$ quartz, $35 \%$ iron oxide and $50 \%$ calcium fluoride. The quartz amounts on the filters were analyzed by the present direct method. The calibration curves (fig. 1), which are based on a pure calcium fluoride matrix, were used when the peak intensities were converted to concentrations. The results (mean \pm standard deviation) for the two series were $4.9 \pm 0.8 \%$ and $17.7 \pm 2.5 \%$, respectively.

These results confirm the assumption that the matrix effects do not seriously limit the usefulness of the method. The mass absorption properties of calcium fluoride can be considered as roughly similar to common silicate minerals and foundry dust. Iron compounds exhibit strong fluorescence and high mass absorption when $\operatorname{CuK} \alpha$ radiation is used in the diffractometer. The iron content of foundry dust may vary from 2 to $20 \%$ and, if so, the inaccuracies caused by mass absorption and enhancement effects are expected to be less than those found in the present experiment. Theoretically, for a $10-\mathrm{mg}$ sample, a maximum relative error of $20 \%$ can be caused by the variation of mass absorption coefficient from 40 to 100 $\mathrm{cm}^{2} / \mathrm{g}$ (equation a). This range includes calcium fluoride and common minerals such as calcite, dolomite, zircon, felspars, micas and mixtures thereof (10). 
The diffractometry of thin layer specimens analyzed directly on collecting organic membranes suffers from high X-ray background scatter from the filter. However, the sloping and uneven base line was taken into account by digital peak recognition and integration. Some care has to be exercised to insure that the filter surface in the specimen holder is taut and unwaved. The nonuniformity of the dust deposit can cause a variation of about $0.05^{\circ}$ in peak positions and, in addition, can cause an undue variation of line intensities. Rotation of the sample is helpful to even out the preferred orientation and nonuniform distribution, but their effects cannot be totally compensated for in this way.

The relative intensities of the bulk specimens agreed with the published values of Fyle quartz (6), while those for the filter deposits did not. The measured ratios of lines $20.85^{\circ}, 26.67^{\circ}$ and $50.15^{\circ}$ were 18:100:12 for the bulk samples and 25:100:6 for the filter samples. It appeared that three phenomena accounted for the difference. The line intensities vary with the $\Theta$ for thin samples as follows:

$$
I=(2 \mathrm{kCm} / \mathrm{A}) \operatorname{cosec} \Theta,
$$

whereas equation a yields an invariable value for an infinitely thick layer:

$$
\mathrm{I}=\mathrm{kC} / \mu \text {. }
$$

Accordingly, the calculated ratios for a thin sample are 23:100:7. Secondly, a thin layer of cleaved quartz crystals on a smooth surface may exhibit a preferred orientation favoring the $3.34 \AA$ line (8). As the deposition depth increases or the filter material becomes more porous, the orientation approaches random. Thirdly, the rough surface of the membrane can cause shadowing of the X-ray beam at low $2 \Theta$ angles. However, the relative line intensities remained practically unaltered and irrespective of the total loading or means of the dust deposition on the filter when the sample size was limited to less than $20 \mathrm{mg}$.

\section{Particle size}

An additional problem in diffractometric analysis is that the peak intensity from an unknown must be compared to some known material for a quantitative estimate. Particle size distribution, crystallographic properties, or the orientation of the standard sample may be different from that of the unknown and result in significant error (11). For the evaluation of the particle size effect, three fractions of Fyle quartz were separated by liquid sedimentation. The mean particle size of the sediments was $1-2,2-5$, and $5-10$ $\mu \mathrm{m}$ when counted by optical microscopy. In comparison to the original standard filters, the 1-2 $\mu \mathrm{m}$ fraction yielded only about $75 \%$ of the intensity for the quartz lines of $20.85^{\circ}, 26.67^{\circ}$ or $50.15^{\circ}$. About $100 \%$ intensity was measured from the two coarse fractions.

Alteration in peak intensity was also found when quartz powders of different particle sizes were measured. The powders were mounted in the diffractometer by means of a bulk specimen holder $10 \mathrm{~mm}$ in diameter. The intensity was maximum for 2- to $3-\mu \mathrm{m}$ particles. An intensity of about $90 \%$ was measured from particles in the size range of $40-50 \mu \mathrm{m}$. The intensity from the coarse fraction was reduced because of the X-ray extinction within the particles, whereas the reduction of intensity from smaller particles was ascribed to their amorphous surface. The pulverizing process creates an amorphous surface layer on the quartz particles approximately $0.03 \mu \mathrm{m}$ thick (3). The mass of this noncrystalline material comprises a significant percentage only in small particles less than $1 \mu \mathrm{m}$ in size.

A proportion of the X-ray intensity reduction from smaller particles can be accounted for by line broadening. The $26.67^{\circ}$ line width was increased by $15 \%$ in the $1-2 \mu \mathrm{m}$ fraction as compared to the coarse fractions. Therefore the peak area measurement is recommended for the quantitative analysis in order to compensate for this phenomenon.

\section{Field samples}

Foundry dust was collected on membrane filters with an open face monitor and by means of personal and stationary samplers. The dust samples represented different iron foundry operations, namely, 
Table 2. Quartz concentrations in foundry samples. Comparison of the direct method with internal standardization.

\begin{tabular}{|c|c|c|c|}
\hline $\begin{array}{l}\text { Total dust } \\
\text { amount on } \\
\text { filter } \\
(\mathrm{mg})\end{array}$ & $\begin{array}{l}\text { Quartz in total } \\
\text { dust, analyzed } \\
\text { directly on } \\
\text { a filter } \\
(\%)\end{array}$ & $\begin{array}{c}\text { Quartz in total } \\
\text { dust }_{2} \text { analyzed } \\
\text { by internal } \\
\text { standardization } \\
(\%)\end{array}$ & $\begin{array}{l}\text { Quartz in respirable } \\
\text { dust, analyzed by } \\
\text { sedimentation and } \\
\text { internal standardization } \\
(\% / 0)\end{array}$ \\
\hline 2.0 & 15 & 16 & too small a sample \\
\hline 3.8 & 7 & 7 & \# \\
\hline 4.8 & 10 & 9 & $»$ \\
\hline 5.5 & 3 & 3 & $》$ \\
\hline 6.7 & 14 & 11 & $》$ \\
\hline 7.5 & 17 & 20 & 2 \\
\hline 8.3 & 82 & 90 & $\gg$ \\
\hline 14.8 & 14 & 13 & $10^{a}$ \\
\hline 15.7 & 12 & 11 & $7 a$ \\
\hline 17.8 & 6 & 7 & $6^{a}$ \\
\hline 19.0 & 14 & 14 & $11^{\mathrm{a}}$ \\
\hline
\end{tabular}

a With $55 \%$ respirable dust.

sand preparation, casting, molding, shakeout and fettling. A series of these samples was analyzed quantitatively by the present direct method and by a procedure in which the dust deposit is removed onto a cover glass and the quartz concentration is measured with calcium fluoride used as an internal standard (21). Table 2 shows a part of the results for comparison. In general the disagreement between the two methods was less than $10 \%$ of the mean value. The fraction of respirable dust does not fluctuate much from one foundry operation to another, and therefore the concentration of respirable quartz could be estimated from the total content. A range of about $30-60 \%$ of respirable dust is typical for a large series of samples (16).

In the case of foundry dust, diffraction line interference must be considered. In the present experiment the quartz line of $20.85^{\circ}$ was used for the quantitation if the qualitative scan of a sample indicated the presence of graphite or zircon; otherwise the more intense $26.67^{\circ}$ peak was preferable. The detection limit of the analytical method is dependent on the composition and amount of the matrix on the filter. For the iron foundry samples with a quartz content of about $10 \%$, a quartz amount of $0.1 \mathrm{mg}$ can be detected. The lowest quartz concentration detectable in large samples is about $2 \%$.

\section{DISCUSSION}

The present work is primarily related to the X-ray analysis of quartz - that is, the last step of assessing its concentration in workplace air. Therefore the precision and accuracy of the analytical method should be compared with other sources of error. When a typical precision of $8 \%$ for a direct quartz analysis (table 1 ) and that of $7 \%$ for air flow measurements with personal samplers are added as squared, a total precision of $11 \%$ for the concentration measurement is achieved. The imprecision of weighing the loaded filters is negligible, because at low loadings, where the dust weight determination is most imprecise, the mass absorption effects are minimal. The precision of the direct method is fully comparable with the results achieved by dust removal and internal standardization (21).

In practice particle orientation or nonuniformity of the filter samples are not significant limitations to the use of the calibration standards made by suspension filtration. However, all analytical methods for free silica share one common problem; the particle size distributions of the sample and the standard are important variables. If the size distribution of the dust sample is too fine, the X-ray response is low compared to a standard. In addition 
the question remains of whether the amorphous layer of quartz particles should be included in the quantitation. When a standard material such as Fyle quartz with a known particle size distribution in the respirable range is selected, the results are consistent. The accuracy of analyzing total quartz content in foundry samples can thus be taken relatively to be about $10 \%$ when the chemical composition and size distribution is roughly known according to the type of dust-producing material or process.

The direct diffractometric method proved to be both convenient and accurate for analyzing quartz on membrane filters. Since dust removal from a filter is time consuming and prone to introduce additional error, it seems preferable to confine the techniques to cases where the respirable fraction of the dust sample must be determined or when severe interferences must be removed by ashing or redeposition. Direct measurement is especially suited for total dust loadings ranging from 1 to $10 \mathrm{mg}$.

\section{ACKNOWLEDGMENTS}

The author wishes to thank Ms. T. Salmi for her skilled technical assistance.

\section{REFERENCES}

1. ALTREE-WILLIAMS, S. Quantitative Xray diffractometry on milligram samples prepared on silver filters. Anal. chem. 49 (1977) $429-432$.

2. ALTREE-WILLIAIMS, S., LEE, J. and MEZIN, N. V. Quantitative X-ray diffractometry on respirable dust collected on Nuclepore filters. Ann. occup. hyg. 20 (1977) $109-126$.

3. ANDERSON, P. L. Free silica analysis of environmental samples - a critical literature review. Am. ind. hyg. assoc. j. 36 (1975) $767-778$.

4. BRADLEY, A. A. The determination of quartz in small samples by an X-ray technique. J. sci. instrum. 44 (1967) 287-288.

5. BUMSTED, H. E. Determination of alphaquartz in the respirable portion of airborne particulates by X-ray diffraction. Am. ind. hyg. assoc. j. 34 (1973) 150-158.

6. CARDFELT, M. and EKSTRÖM, T. An- vändning av röntgendiffraction för arbetshygienisk analys av partikulära luftföroreningar (Utbildningsrapport 1978: 8). Arbetarskyddsstyrelsen, Stockholm 1978. $58 \mathrm{p}$

7. CROSBY, M. T. and HAMER, P. S. The determination of quartz on personal sampler filters by X-ray diffraction. Ann. occup. hyg. 14 (1971) 65-70.

8. EDMONDS, J. W., HENSLEE, W. W. and GUERRA, R. E. Particle size effects in the determination of respirable $\alpha$-quartz by X-ray diffraction. Anal. chem. 49 (1977) $2196-2203$.

9. GORDON, R. L. and HARRIS, G. W. Effect of particle size on the determination of quartz by X-ray diffraction. Nature 175 (1955) 1135.

10. HEIDERMANNS, G. Die röntgenographische Quartzgehaltsbestimmung in dünnen Schichten auf Filtern abgeschiedener Feinstaubproben. Staub Reinhalt. Luft 34 (1974) 260-264.

11. HEIDERMANNS, G. Ergebnisse von Untersuchungen zur Definition eines Standards für die Quartzbestimmung von Feinstaubproben. Staub Reinhalt. Luft 38 (1978) $420-423$.

12. KRANTZ, S. and HABERMAN, H. Utveckling av en metod för direktanalys av kvarts på membranfilter (Undersökningsrapport AMTE 106/74). Arbetarskyddsstyrelsen, Stockholm 1974. $60 \mathrm{p}$.

13. KRANTZ, S. and SCULLMAN, J. Infrarödspektrometrisk analys av kvarts (Arbete och hälsa 1976:1). Arbetarskyddsverket, Stockholm 1976. $45 \mathrm{p}$.

14. LEROUX, J., DAVEY, A. B. C. and PAILLARD, A. Proposed standard methodology for the evaluation of silicosis hazards. Am. ind. hyg. assoc. j. 34 (1973) 409-417.

15. MILLIPORE CORPORATION. Millipore catalogue and purchasing guide. Bedford, MA $1977,48 \mathrm{p}$.

16. SILTANEN, E., KOPONEN, M., KOKKO, A., ENGSTROMM, B. and REPONEN, J. Dust exposure in Finnish foundries. Scand. j. work environ. \& health 2 (1976): suppl. $1,19-31$.

17. SWEET, D. V., WOLOWICZ, F. R. and CRABLE, J. A. Spectrophotometric determination of free silica. Am. ind. hyg. assoc. j. 34 (1973) $500-506$.

18. TALVITIE, N. A. Determination of free silica: Gravimetric and spectrometric procedures applicable to airborne and settled dust. Ind. hyg. j. 3 (1964) 169-178.

19. TALVITIE, N. A. and BREWER, L. W. $\mathrm{X}$-ray diffraction analysis of industrial dusts. Am. ind. hyg. assoc. j. 23 (1962) 214-216.

20. TOMA, S. Z. and GOLDBERG, S. A. Direct infrared analysis of alpha quartz deposited on filters. Anal. chem. 44 (1972) $431-432$.

21. TOSSAVAINEN, A. and KOKKO, A. Precision and accuracy of foundry dust exposure estimates from air sampling data. Scand. j. work environ. \& health 2 (1976): suppl. 1, 13-18. 